The Journal of Laryngology \& Otology

http://journals.cambridge.org/JLO

Additional services for The Journal of Laryngology \& Otology:

Email alerts: $\underline{\text { Click here }}$

Subscriptions: $\underline{\text { Click here }}$

Commercial reprints: $\underline{\text { Click here }}$

Terms of use : $\underline{\text { Click here }}$

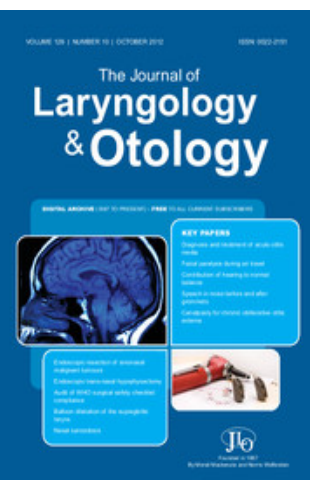

\title{
Cochlear implantation in the presence of chronic suppurative otitis media
}

\author{
P. R. Axon, D. J. Mawman, T. Upile and R. T. Ramsden
}

The Journal of Laryngology \& Otology / Volume 111 / Issue 03 / March 1997, pp 228 - 232

DOI: 10.1017/S0022215100136977, Published online: 29 June 2007

Link to this article: http://journals.cambridge.org/abstract_S0022215100136977

How to cite this article:

P. R. Axon, D. J. Mawman, T. Upile and R. T. Ramsden (1997). Cochlear implantation in the presence of chronic suppurative otitis media. The Journal of Laryngology \& Otology, 111, pp 228-232 doi:10.1017/S0022215100136977

Request Permissions : $\underline{\text { Click here }}$ 


\title{
Cochlear implantation in the presence of chronic suppurative otitis media
}

\author{
P. R. Axon, D. J. Mawman*, T. Upile, R. T. Ramsden
}

\begin{abstract}
Nine patients are presented who underwent cochlear implantation in the presence of chronic suppurative otitis media. Four had a simple tympanic membrane perforation, four had a pre-existing mastoid cavity and one had cholesteatoma in the ear chosen for implantation. Patients with a simple perforation had a staged procedure with myringoplasty followed by cochlear implantation after an interval of three months. Patients with cholesteatoma or with an unstable mastoid cavity were also staged. A mastoidectomy or revision mastoidectomy was performed with obliteration of the middle ear and mastoid using a superiorly pedicled temporalis muscle flap and blind sac closure of the external meatal skin. After a further six months a second stage procedure was performed to confirm that the middle-ear cleft was healthy and to insert the implant. Patients presenting with a stable mastoid cavity underwent obliteration of the cavity and implantation of the electrode as a one-staged procedure. To date there have been no serious problems such as graft breakdown, recurrence of disease or implant extrusion, and all patients are performing well.
\end{abstract}

Key words: Cochlear implant; otitis media, chronic suppurative

\section{Introduction}

Cochlear implantation has been shown to be a reliable method of rehabilitation for certain profoundly deaf or deafened individuals Summerfield and Marshall (1995). Most patients assessed for cochlear implantation have middle ears which are free of pathology, and in these patients cochlear implantation is usually an uncomplicated singlestaged operation. Chronic suppurative otitis media (CSOM) may be encountered however, either as the cause of the profound deafness or as a noncontributory chance finding. Such patients present the surgeon with a potential problem. Implantation of a foreign body into a septic field would seem foolhardy with rejection a worrying possibility; furthermore the introduction of infection into the cochlea through the portal of implantation could have serious effects on the surviving neural elements which one hopes to stimulate with the implant. This paper describes the experience of the Manchester Royal Infirmary cochlear implant programme in managing nine patients with a profound hearing loss and CSOM.

\section{Patients and procedures}

Between 1988 and 1996 a total of 157 patients have received cochlear implants in the Manchester.
Royal Infirmary/University of Manchester Programme (105 adults and 52 children). Of these, nine (5.7 per cent) were found to have CSOM either as the cause of the profound hearing loss or as an incidental finding. The obvious and usual reason for choosing to implant an ear with CSOM was the presence of a bilateral disease, but other indications were the presence of a relative contraindication on the contralateral side eg labyrinthectomy for Menière's disease (one patient), a congenital hearing loss (one patient) and the presence of some aidable residual hearing (one patient). The ages of the patients at implantation ranged from four to 62 years of age with a mean of 47.6 years. The duration of profound deafness ranged from one to 44 years with a mean of 11.5 years (Table I).

Standard pre-operative assessments included high definition axial CT scans of the petrous bones to exclude as far as possible new bone formation in the cochlea. Pure tone audiometry and speech audiometry with, and without, hearing aids was performed together with assessment of lip-reading skills. Promontory stimulation testing was not routinely performed. Post-implantation testing included free field audiometry (FFA) using warble tones at octave frequencies from $250 \mathrm{~Hz}$ to $4000 \mathrm{~Hz}$, Bench Kowal Bamford (BKB) sentence tests, and consonant confusion tests (VCV). Environmental sound recog-

From the Department of Otolaryngology, Manchester Royal Infirmary and the łManchester cochlear implant programme*, Manchester, UK.

Accepted for publication: 29 December 1996. 
TABLE I

PATIENT DETAILS

\begin{tabular}{lrrlll}
\hline Patient & Age & Duration of deafness & CSOM & Surgery & Implant and insertion \\
\hline 1 & 53 & 13 & TM perforation & Myringoplasty & Nucleus 22+5 \\
2 & 50 & 6 & TM perforation & Myringoplasty & Medel 8 \\
3 & 4 & 1 & TM perforation & Myringoplasty & Nucleus 22+10 \\
4 & 47 & 10 & TM perforation & Myringoplasty & Nucleus 22+0 \\
5 & 62 & 2 & Mastoid cavity & Single staged procedure & Nucleus 22+6 \\
6 & 56 & 44 & Mastoid cavity & Single staged procedure & Nucleus 18 \\
7 & 59 & 5 & Mastoid cavity & 2 staged procedure & Nucleus 22+10 \\
8 & 47 & 6 & Mastoid cavity & 2 staged procedure & Medel 8 \\
9 & 50 & 16 & Cholesteatoma & 2 staged procedure & Medel 8 \\
\hline
\end{tabular}

nition (ENV) was scored. The tests were carried out at one month, nine months and 18 months after switch on.

Four patients presented with simple perforations of the tympanic membrane, without cholesteatoma. In none was the middle-ear disease responsible for the hearing loss. In three there were bilateral perforations and in two of these individuals the perforations accompanied profound hearing loss of unknown cause. The third was a child who had been deafened, and suffered perforations during treatment for acute lymphoblastic leukaemia. In the fourth the contralateral ear had had a labyrinthectomy for Menière's disease and was considered unsuitable. The perforations were repaired using a temporalis fascia underlay technique. Three healed at the primary operation. One required a revision myringoplasty because of graft failure. All had had an intact drum for at least three months prior to implantation. All patients had satisfactory CT images with no sign of ossification in the lumen of the cochlea. Implantation was uncomplicated in all cases with complete insertion of the whole electrode array.

Five patients had, or had had CSOM with cholesteatoma. In three, there was a stable, well epithelialized mastoid cavity, and an air-containing mesotympanum. Two of these patients were treated by employing a one-stage technique which entailed removal of the fibro-epithelial lining of the middle ear and mastoid, and the skin of the bony external auditory canal, followed by obliteration of the mastoid cavity with a pedicled temporalis muscle flap, which also serves to protect the electrode array, and a blind sac closure of the meatal skin. The third of this group had a two stage operation. At the first stage the fibro-epithelial lining of the mastoid cavity was carefully elevated forwards up to, and beyond, the facial ridge and the middle ear opened to allow access to the round window. The flap of temporalis muscle was then cut and turned into the mastoid bowl and middle ear and the fibro-epithelial layer then laid back over it. No blind sac closure was performed. At the second stage three months later, dissection deep to the muscle flap allowed easy access to the round window and a Nucleus 22 channel device was inserted through a separate cochleostomy without difficulty. No problem was enountered with any of these patients. All received Nucleus 22 channel devices although only a partial insertion (18 channels) was possible in patient 6 (Table I)

Two patients had active CSOM at the time of presentation. Patient 8 a 45 -year-old man had been born with a total right-sided hearing loss and lost the hearing in the left ear in adult life. An attic cholesteatoma was present, although it was by no means certain that this was responsible for the loss of hearing. From consideration of neural plasticity issues it was felt that despite the CSOM the left ear was the preferred ear for implantation. A twostage procedure was proposed. At the first operation a radical mastoidectomy was carried with eradication of a fairly circumscribed cholesteatoma from the attic and mastoid antrum. The cavity was obliterated using a pedicled temporalis muscle flap and a blind sac closure performed. At the second stage procedure, after an interval of six months. A healthy cavity was found. The muscle flap was dissected off the promontory and a Nucleus 22 channel device was inserted through a separate cochleostomy.

Patient 9 had had a bilateral CSOM with cholesteatoma treated with modified mastoidectomies was totally deaf. A Medel implant had been inserted into the left side at another centre. No attempt had been made to provide soft tissue protection for the electrode array which was in effect covered by no more than the epithelial lining of the middle ear and mastoid. Not many months later the patient presented with the electrode protruding from the external meatus, surrounded by pus and granulation tissue. A two-stage procedure was planned. At the first stage the electrode was removed, and a revision mastoidectomy performed with eradication of residual cholesteatoma, obliteration the Eustachian tube opening, obliteration of the mastoid with a temporalis muscle flap, and a blind sac closure of the external meatus. On this occasion a silastic sheet was placed between the muscle flap and the promontory, to facilitate access at the second stage. The second operation was performed after a further six months. No problem was found in identifying the promontory. The first implant had been inserted through the round window. The replacement, also a Medel device was inserted through a separate cochleostomy in front of the round window. Despite the fact that the scala had been open for at least six months there was very little fibrosis in its lumen and, such as there was, was by-passed by the cochleostomy. The ear healed uneventfully. 
TABLE II

RESULTS OF PRE-OPERATIVE LIP-READING WITH HEARING AID AND POST-OPERATIVE LIP-READING WITH ELECTRICAL STIMULATION

\begin{tabular}{|c|c|c|c|c|c|c|}
\hline \multirow[b]{2}{*}{ Patient } & \multicolumn{3}{|c|}{ BKB } & \multicolumn{3}{|c|}{ VCV } \\
\hline & ALR & $\begin{array}{c}\text { PI } 9 \\
\text { LR+ES }\end{array}$ & $\begin{array}{c}\text { PI } 18 \\
\text { LR+ES }\end{array}$ & ALR & $\begin{array}{c}\text { PI } 9 \\
\text { LR+ES }\end{array}$ & $\begin{array}{c}\text { PI } 18 \\
\text { LR+ES }\end{array}$ \\
\hline 1 & 50 & 84 & 88 & 39.9 & 65.1 & 60.9 \\
\hline 2 & 76 & 98 & - & 58.8 & - & - \\
\hline 4 & 74 & 90 & 100 & 14.7 & 50.4 & 75.6 \\
\hline 5 & 32 & 96 & - & 29.4 & - & - \\
\hline 6 & 62 & 98 & - & 37.8 & - & - \\
\hline 7 & 68 & 96 & 100 & 42.0 & 96.6 & - \\
\hline 8 & 36 & 94 & 98 & 29.4 & 79.8 & 84 \\
\hline
\end{tabular}

\section{Results}

All patients had an uneventful post-operative recovery. One myringoplasty patient (4) suffered a subsequent episode of otitis media in the implanted ear, and this settled promptly on a short course of antibiotics, without any adverse effects on the drum or the performance of the implant.

$\mathrm{BKB}, \mathrm{VCV}$ and ES scores are available at nine months or earlier for seven out of the nine patients and at 18 months for five of the nine. Patient 3 is a child and has not had the conventional adult assessments shown below. Patient 9 is not available for testing for geographical and linguistic reasons. Nevertheless one of the authors has heard her converse easily in her own language with little reliance on lip reading and she is very happy with the result of her implantation.

$B K B$ results with $L R+E S$ were 80 per cent or better at nine months with a mean of 93 per cent $(84$ per cent to 98 per cent). At 18 months, the mean $\mathrm{LR}+\mathrm{ES}$ was 96.5 per cent ( 88 per cent to 100 per cent). In every case there was an improvement in the scores between nine and 18 months (Table 2, Figure 1). ES scores at nine months ranged from 0 per cent to 94 per cent with a mean score of 52 per cent and at 18 months ranged from 72 per cent to 88 per cent with a mean of 82.7 per cent (Table III).

VCV results with $\mathrm{LR}+\mathrm{ES}$ at nine months ranged from 50.4 per cent to 96.6 per cent with a mean of 73

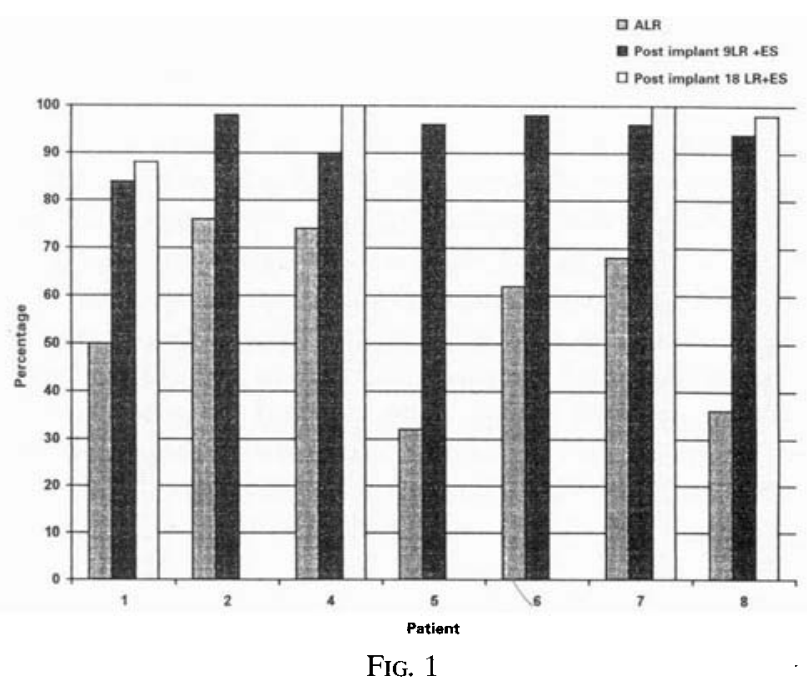

Analyses of the change in accuracy of identification of words in sentences (BKB) comparing performance when lip-reading was supplemented by a hearing aid pre-operatively (ALR) and by implant post-operatively (LR+ES). per cent. At 18 months, the mean LR+ES was 73.5 per cent ( 60.9 per cent to 84 per cent) (Table II, Figure 2). ES scores at nine months ranged from 31.5 per cent to 81.9 per cent with a mean score of 45.2 per cent and at 18 months ranged from 25.2 per cent to 67.2 per cent with a mean of 43.4 per cent (Table III).

The mean ENV results at one month was 49.3 per cent ranging from 37.5 per cent to 75 per cent. At nine months, a mean score of 66.9 per cent ranging from 45 per cent to 85 per cent and at 18 months a mean score of 58.3 per cent ranging from 42.5 per cent to 77.5 per cent (Table III, Figure 3 ).

\section{Discussion}

Cochlear implantation has been performed in a series of nine patients with CSOM and profound deafness. All of these patients have derived great benefit from the surgery, and it is quite clear to us that they represent a group which though more difficult to manage than the 'usual' cochlear implant patient, should be seriously considered by the teams engaged in this exciting field of work. Each individual should have his or her treatment individualized, but even so certain general observations can be made. If a well-performed operation is to seal off the middle ear, or obliterate the mastoid, there seems to be little risk of rejection of the implant. A simple dry perforation can be easily repaired and should present no long-term problems. It has been our practice to perform two-stage surgery in this situation and to observe a soundly healed drum for three months before proceeding to implantation. No particular technical problems need be expected at implantation. Subsequent acute otitis media has not led to rejection although it would seem sensible to treat such infections vigorously.

Management becomes more complicated in the presence of a previous mastoid cavity, be it healthy or infected, or if cholesteatoma is present in a previously un-operated ear. The main issues concern the questions of staging and of obliteration as well as the actual techniques. Certainly in an ear with cholesteatoma present, a two-stage procedure is recommended, with eradication of disease at the first operation followed by insertion of the implant six months later if the ear is disease free. It is also essential to create a strong protective layer of tissue with which to cover the implant. Simply to insert an electrode under the epithelial lining of the mastoid is 
TABLE III

RESULTS AT 1, 9 AND 18 months with electrical stimulation alone

\begin{tabular}{|c|c|c|c|c|c|c|c|}
\hline \multirow[b]{2}{*}{ Patient } & \multicolumn{2}{|c|}{ BKB } & \multicolumn{2}{|c|}{$\mathrm{VCV}$} & \multicolumn{3}{|c|}{ ENV } \\
\hline & PI 9 ES & PI 18 ES & PI 9 ES & PI $18 \mathrm{ES}$ & PI 1 ES & PI 9 ES & PI $18 \mathrm{ES}$ \\
\hline$\overline{1}$ & 0 & 0 & 31.5 & 25.2 & 37.5 & 45 & 42.5 \\
\hline 2 & 72 & - & - & - & 37.5 & - & - \\
\hline 4 & 50 & 72 & 31.5 & 37.8 & 45 & 60 & 55 \\
\hline 5 & 38 & - & - & - & 50 & - & - \\
\hline 6 & 68 & - & - & - & 50 & - & - \\
\hline 7 & 94 & 88 & 81.9 & - & 75 & 85 & - \\
\hline 8 & 58 & 88 & 35.7 & 67.2 & 50 & 77.5 & 77.5 \\
\hline
\end{tabular}

to court disaster and virtually guarantee rejection of the device as was found in Patient 8 . Our technique has been to swing a pedicled flap of temporalis muscle into the mastoid and middle ear, and either to perform blind sac closure of the meatal skin, or to cover the muscle with the preserved lining of the mastoid if it is healthy. If the mastoid and middle ear are disease free and stable, the implant may be inserted at the same operation. If there is any doubt about eradication of disease a two-stage procedure must be performed. Elevation of the fibro-epithelial lining of the mastoid should be carried out meticulously whether it is to be preserved or discarded, to ensure that no squamous epithelium is left behind and for the same reason the matsoid bone and any remaining air cells should be drilled out. Quite considerable drilling may be necessary in the region of the upper edge of the mastoidectomy in order to provide a smooth surface for the temporalis muscle flap. As in any revision mastoidectomy extra care is appropriate when elevating soft tissue off the facial nerve or its canal. If the operation is to be staged one should consider whether to insert a silastic sheet between the muscle flap and the promontory. It is not necessary in the majority of cases, as no great difficulty is encountered dissecting the flap off the promontory at the second-stage procedure. It is

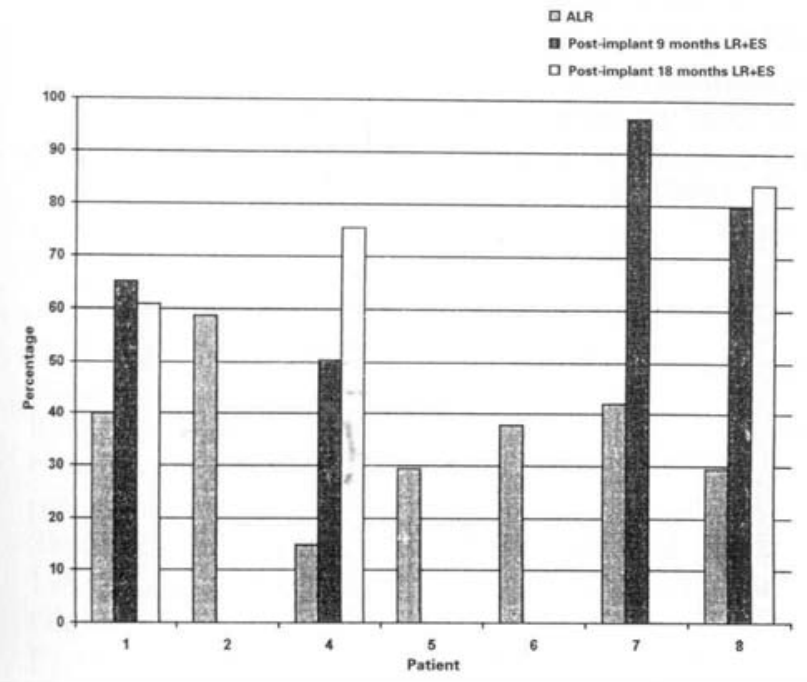

FIG. 2

Analyses of the change in accuracy of identification of vowelconsonant-vowel syllables (VCV) comparing performance when lip-reading was supplemented by a hearing aid (ALR) pre-operatively and by implant post-operatively (LR+ES). advisable however if the facial nerve is dehiscent so as to prevent adhesions between the muscle flap and the nerve.

One of the worries with obliteration operations is the fear of entrapment of squamous epithelium out of sight and this remains a niggling anxiety in these cases. It is a problem that is compounded by the fact that MR, which might allow one to monitor developing cholesteatoma is of no use in cochlear implant patients, not only because of the presence of the magnet, but because of the signal void which occurs round implanted metal. The patients in this series have had no obvious recurrence and undergo close clinical monitoring.

There are relatively few reports in the literature of cochlear implantation in the presence of CSOM. Schlondorff et al. (1989) describe a technique of implantation in a mastoid cavity by which a full thickness post-auricular skin flap was swung into the mastoid bowl to protect the implant. Clark et al. (1995) described the implantation of three patients with CSOM without cholesteatoma. All three had recurrence of their middle ear disease requiring further surgery. One patient developed infection within the otic capsule via the cochleostomy and had to have his implant removed. They concluded that if implantation was to be considered in the presence of

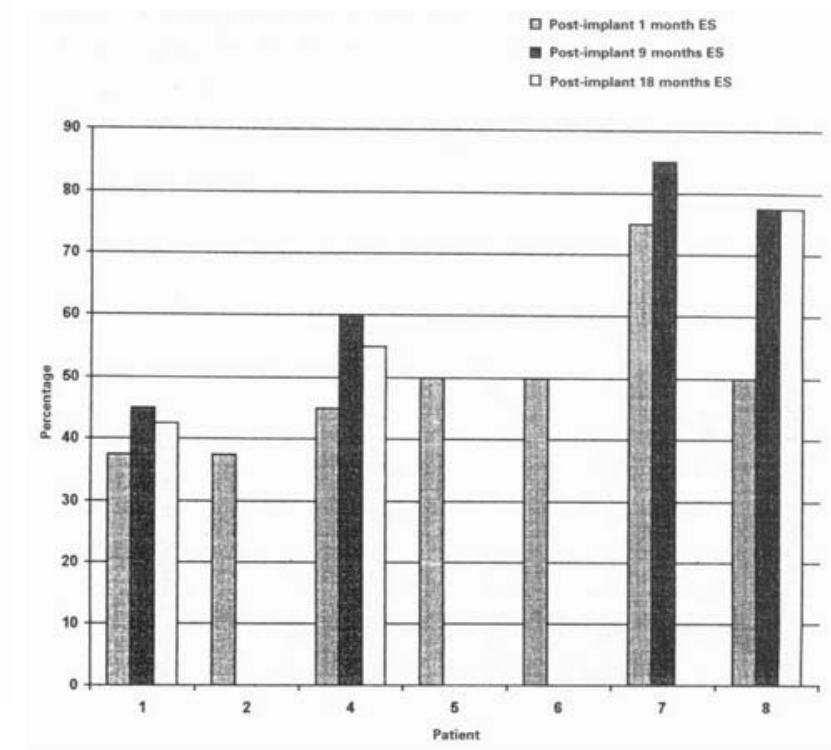

FIG. 3

Analyses of the change in accuracy of identification of environmental sounds (ENV) by electrical stimulation (ES) comparing performance at 1,9 and 18 months post-implant. 
CSOM, a radical mastoidectomy with obliteration should be considered. The possibility of infection entering the inner ear through the cochleostomy has been considered by Franz et al. (1987) and Jackler et al. (1986). Irving and Gray (1994) have adopted this principle in cases of CSOM without cholesteatoma with a two-stage procedure three to six months apart.

\section{References}

Clarke, G. M., Pyman, B. C., Webb, R. L. (1995) Chronic middle ear disease and cochlear implantation. Annals of Otology, Rhinology and Laryngology (Suppl. 166): 406-408.

Franz, B. K. H., Aud, D., Clark, G. M. (1987) Effect of experimentally induced otitis media on cochlear implants. Annals of Otology, Rhinology and Laryngology 96: 174-177.

Irving, R. M., Gray, R. F. (1994) Cochlear implants in chronic suppurative otitis media: preparing the septic ear for a sterile device. (Hochmair-Desoyer II, Hochmair ES, eds.) Advances in Cochlear Implants Vienna, Austria, Manz, pp 223-227.
Jackler, R. K., O'Donoghue, G. M., Schindler, R. A. (1986) Cochlear implantation: Strategies to protect the implanted cochlear from middle ear infection. Annals of Otology, Rhinology and Laryngology 95: 66-70.

Schlondorff, G., Hermes, H., Weck, L. (1989) Cochlear implants bei patientten mit radikalhohle. Head and Neck, Otolaryngology 37 (10): 423-425.

Summerfield, A. Q., Marshall, D. H. (1995) Cochlear Implantation in the UK 1990-1994. Main report, report by the MRC Institute of Hearing Research HMSO, London, UK pp 63-89.

Address for correspondence:

Mr P. R. Axon,

1 Westgate,

Hale,

Altrincham WA15 9AY.

Fax: 01612768511 